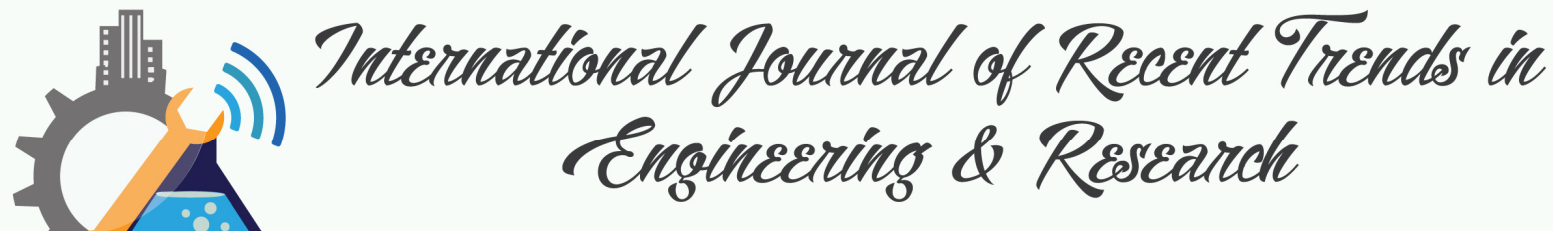

\section{Vernam Encypted Text in End of File Hiding Steganography Technique}

\author{
Wirda Fitriani $^{1}$, Robbi Rahim ${ }^{2}$, Boni Oktaviana ${ }^{3}$, Andysah Putera Utama Siahaan ${ }^{4}$ \\ ${ }^{1,4}$ Faculty of Computer Science, Universitas Pembanguan Panca Budi, Medan, Indonesia \\ ${ }^{2}$ Department of Health Information, Akademi Perekam Medik dan Infokes Imelda, Medan, Indonesia \\ ${ }^{3}$ Department of Informatics, Sekolah Tinggi Teknik Harapan, Medan, Indonesia \\ ${ }^{2,4}$ Student of Universiti Malysia Perlis, Kangar, Malaysia
}

\begin{abstract}
The concealment of information in the image can be done with some specific techniques. One of the techniques used is End of File. In the insertion of this information, a series of characters will be converted to ASCII code and each byte will be inserted at the end of the RGB image in descending order. The insertion can be done in Red, Green, Blue or on all of them. The downside of this insertion is that if the bits are extracted in sequence, this will produce the original information that has been previously inserted. In large data usage with a limited number of pixels, the stego image will display an oddity. To make the information more secure, an encryption technique needs to be applied. The encryption used is Vernam. This method has very high speed. The data embedded in the image will be more secure.
\end{abstract}

Keywords - Cryptography, Steaganograpy, End of File

\section{INTRODUCTION}

End of File is a steganography technique that is often used in color images. This technique has two types of ways, by adding information or byte codes at the end of file or changing the pixel value from the end to the beginning. However, this technique is vulnerable to attack. As long as there are no suspicious signs on the image, the information will remain secure in place. If suspicions arise, the extraction of information sequentially generates byte codes which can then produce the important information.Basically, steganography only aims to hide information from the naked eye [4]. Steganography has absolutely no technique to conceal or encode the information to be incomprehensible. The integration of cryptography and steganography is very important to maintain the balance of information residing in the image. Steganography aims to trick someone's view of certain information. But if the view is already fixed on that information, cryptography will take over to maintain data security [2]. Although the information is successfully extracted, it is hoped that the information remains unintelligible.

\subsection{End of File}

\section{THEORIES}

Steganography has many ways to hide information. Steganography takes advantage of the human eye's weakness to process color images [6][7]. Usually, the human eye is not very sensitive to see the color differences in a color image. So the message is invisible or audible [3]. The End of File technique is one of the techniques always used in steganography to store information on color images. Usually, this technique is applied by adding information on end of file or pixel end. The amount of information inserted depends on the size of the image file. The information that can be inserted actually has an unlimited size. However, the image will be easily recognized by someone that there is information in it. 
In the End of File technique, there are several methods that can be applied to this model:

- Substitution. Initial data will be replaced with confidential information. This technique does not change the original file size because it only redeems two pieces of data. The downside is the image quality will decrease. The bigger the information, the more visible the image quality difference.

- Transform Domains. In this method, the information will be inserted in the transform space and will be very good if the use of this model is done on the color image

- Spread Spectrum. This is a transmitting technique Information by using pseudo-noise code.

\subsection{Vernam Cipher}

Cryptography is a method that must be used to secure data. By doing this, important information will be kept confidential [5]. Information can not be avoided from the crime of data theft but information can be secured by messing up its contents so it is difficult to find the contents of the original message [1][8].Vernam cipher is an encryption method that is done by transforming each bit separately with the other bits. This algorithm uses XOR operation. Every bit in the plaintext will be XOR process with another bit on key. Results from encryption. In the stream cipher, the decryption process is done by re-doing the XOR process between the ciphertext and the key. The key length is the number of bytes on the plaintext row. So the keys are often repeated to produce an equal number of lengths with the number of characters in the plaintext.

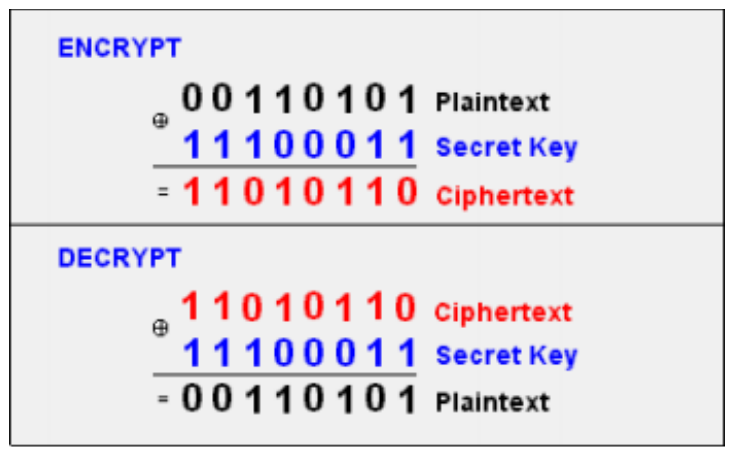

Figure 1.XOR process

Figure 1 illustrates the XOR process of the Vernam cipher. Each bit in the plaintext will be transformed to a secret key. To restore, the same process will be done so that it returns plaintext.

\section{RESULT AND DISCUSSION}

At this stage, it will be tested using a $8 \times 8$ pixel image. The image will be inserted information that will be first encrypted. Table 1 to 3 show the initial RGB byte.

Table 1. Red byte order

\begin{tabular}{|r|r|r|r|r|r|r|r|}
\hline 116 & 48 & 41 & 186 & 180 & 217 & 148 & 212 \\
\hline 28 & 19 & 215 & 194 & 149 & 170 & 187 & 174 \\
\hline 51 & 138 & 253 & 68 & 61 & 234 & 165 & 128 \\
\hline 129 & 228 & 65 & 118 & 102 & 244 & 126 & 216 \\
\hline 187 & 167 & 185 & 152 & 159 & 216 & 233 & 209 \\
\hline 160 & 233 & 78 & 163 & 43 & 21 & 9 & 240 \\
\hline 105 & 104 & 220 & 122 & 157 & 229 & 102 & 161 \\
\hline 246 & 65 & 181 & 244 & 250 & 253 & 79 & 136 \\
\hline
\end{tabular}


Table 2. Green byte order

\begin{tabular}{|r|r|r|r|r|r|r|r|}
\hline 55 & 37 & 203 & 83 & 95 & 0 & 183 & 227 \\
\hline 159 & 29 & 149 & 170 & 239 & 81 & 85 & 80 \\
\hline 230 & 4 & 80 & 153 & 19 & 18 & 64 & 209 \\
\hline 185 & 49 & 208 & 13 & 126 & 120 & 54 & 25 \\
\hline 100 & 25 & 61 & 213 & 231 & 131 & 159 & 163 \\
\hline 187 & 118 & 170 & 210 & 194 & 197 & 197 & 120 \\
\hline 102 & 190 & 243 & 213 & 148 & 11 & 35 & 255 \\
\hline 238 & 60 & 120 & 174 & 76 & 169 & 190 & 229 \\
\hline
\end{tabular}

Table 3. Blue byte order

\begin{tabular}{|r|r|r|r|r|r|r|r|}
\hline 96 & 158 & 85 & 214 & 122 & 181 & 179 & 165 \\
\hline 242 & 75 & 241 & 92 & 55 & 110 & 154 & 242 \\
\hline 143 & 28 & 75 & 167 & 245 & 115 & 216 & 40 \\
\hline 45 & 176 & 252 & 40 & 235 & 248 & 59 & 38 \\
\hline 94 & 112 & 242 & 18 & 158 & 240 & 7 & 148 \\
\hline 48 & 19 & 85 & 212 & 61 & 153 & 9 & 217 \\
\hline 218 & 207 & 34 & 133 & 172 & 14 & 220 & 2 \\
\hline 86 & 214 & 225 & 108 & 155 & 141 & 174 & 151 \\
\hline
\end{tabular}

Plaintext to be inserted is "UNIVERSE". This text will first be converted to byte code and then encryption process to produce ciphertext. For more, the calculations below will explain everything.

\section{Table 4. Plaintext}

\begin{tabular}{|c|c|c|c|c|c|c|c|}
\hline $\mathrm{U}$ & $\mathrm{N}$ & $\mathrm{I}$ & $\mathrm{V}$ & $\mathrm{E}$ & $\mathrm{R}$ & $\mathrm{S}$ & $\mathrm{E}$ \\
\hline 85 & 78 & 73 & 86 & 69 & 82 & 83 & 69 \\
\hline
\end{tabular}

Table 5. Bit Code of Plaintext

\begin{tabular}{|c|c|c|}
\hline $\mathrm{U}$ & 85 & 01010101 \\
\hline $\mathrm{N}$ & 78 & 01001110 \\
\hline $\mathrm{I}$ & 73 & 01001001 \\
\hline $\mathrm{V}$ & 86 & 01010110 \\
\hline $\mathrm{E}$ & 69 & 01000101 \\
\hline $\mathrm{R}$ & 82 & 01010010 \\
\hline $\mathrm{S}$ & 83 & 01010011 \\
\hline $\mathrm{E}$ & 69 & 01000101 \\
\hline
\end{tabular}

Table 4 is the byte value of the plaintext while table 5 is the bit value that has been extracted from the plaintext. Every bit will be processed against the secret key. For example, the key is "KEYS". This key only has 4 characters while the number of characters in the plaintext is 8 characters. This resulted in the key being repeated to meet the number of plaintext characters. The key will be "KEYSKEYS" as shown in table 6 and 7. 
Table 6. Key

\begin{tabular}{|c|c|c|c|c|c|c|c|}
\hline $\mathrm{K}$ & $\mathrm{E}$ & $\mathrm{Y}$ & $\mathrm{S}$ & $\mathrm{K}$ & $\mathrm{E}$ & $\mathrm{Y}$ & $\mathrm{S}$ \\
\hline 75 & 69 & 89 & 83 & 75 & 69 & 89 & 83 \\
\hline
\end{tabular}

Table 7. Bit Code of Key

\begin{tabular}{|c|l|l|}
\hline$K$ & 75 & 01001011 \\
\hline$E$ & 69 & 01000101 \\
\hline$Y$ & 89 & 01011001 \\
\hline$S$ & 83 & 01010011 \\
\hline$K$ & 75 & 01001011 \\
\hline$E$ & 69 & 01000101 \\
\hline$Y$ & 89 & 01011001 \\
\hline$S$ & 83 & 01010011 \\
\hline
\end{tabular}

$\mathrm{C} 1=\mathrm{P} 1 \square \mathrm{K} 1$

$=85 \square 75$

$=01010101 \square 01001011$

$=00011110$

$=30$

$\mathrm{C} 2=\mathrm{P} 2 \square \mathrm{K} 2$

$=78 \square 69$

$=01001110 \square 01000101$

$=00001011$

$=11$

$\mathrm{C} 3=\mathrm{P} 3 \square \mathrm{K} 3$

$=73 \square 89$

$=01001001 \square 01011001$

$=00010000$

$=16$

$\mathrm{C} 4=\mathrm{P} 4 \square \mathrm{K} 4$

$=86 \square 83$

$=01010110 \square 01010011$

$=00000101$

$=5$

$\mathrm{C} 5=\mathrm{P} 5 \square \mathrm{K} 5$

$=69 \square 75$

$=01000101 \square 01001011$

$=00001110$

$=14$

$\mathrm{C} 6=\mathrm{P} 6 \square \mathrm{K} 6$

$=82 \square 69$

$=01010010 \square 01000101$

$=00010111$ 


$$
\begin{aligned}
& =23 \\
\mathrm{C} 7 & =\mathrm{P} 7 \square \mathrm{K} 7 \\
& =83 \square 89 \\
& =01010011 \square 01011001 \\
& =00001010 \\
& =10 \\
\mathrm{C} 8 & =\mathrm{P} 8 \square \mathrm{K} 8 \\
& =69 \square 83 \\
& =01000101 \square 01010011 \\
& =00010110 \\
& =22
\end{aligned}
$$

The following table is the result of the XOR process performed on both characters. The next process is substituting those values into the pixel table.

Table 8. Encryption result

\begin{tabular}{|c|c|}
\hline Byte & Biner \\
\hline 30 & 00011110 \\
\hline 11 & 00001011 \\
\hline 16 & 00010000 \\
\hline 5 & 00000101 \\
\hline 14 & 00001110 \\
\hline 23 & 00010111 \\
\hline 10 & 00001010 \\
\hline 22 & 00010110 \\
\hline
\end{tabular}

Insertion can be done on Red, Green or Blue. The table below describes the insertion made after the Vernam encryption process is complete.

Table 9. Embedding in Red

\begin{tabular}{|r|r|r|r|r|r|r|r|}
\hline 116 & 48 & 41 & 186 & 180 & 217 & 148 & 212 \\
\hline 28 & 19 & 215 & 194 & 149 & 170 & 187 & 174 \\
\hline 51 & 138 & 253 & 68 & 61 & 234 & 165 & 128 \\
\hline 129 & 228 & 65 & 118 & 102 & 244 & 126 & 216 \\
\hline 187 & 167 & 185 & 152 & 159 & 216 & 233 & 209 \\
\hline 160 & 233 & 78 & 163 & 43 & 21 & 9 & 240 \\
\hline 105 & 104 & 220 & 122 & 157 & 229 & 102 & 161 \\
\hline 22 & 10 & 23 & 14 & 5 & 16 & 11 & 30 \\
\hline
\end{tabular}

Table 10. Embedding in Green

\begin{tabular}{|r|r|r|r|r|r|r|r|}
\hline 55 & 37 & 203 & 83 & 95 & 0 & 183 & 227 \\
\hline 159 & 29 & 149 & 170 & 239 & 81 & 85 & 80 \\
\hline 230 & 4 & 80 & 153 & 19 & 18 & 64 & 209 \\
\hline
\end{tabular}




\begin{tabular}{|r|r|r|r|r|r|r|r|}
\hline 185 & 49 & 208 & 13 & 126 & 120 & 54 & 25 \\
\hline 100 & 25 & 61 & 213 & 231 & 131 & 159 & 163 \\
\hline 187 & 118 & 170 & 210 & 194 & 197 & 197 & 120 \\
\hline 102 & 190 & 243 & 213 & 148 & 11 & 35 & 255 \\
\hline 22 & 10 & 23 & 14 & 5 & 16 & 11 & 30 \\
\hline
\end{tabular}

Table 11. Embedding in Blue

\begin{tabular}{|r|r|r|r|r|r|r|r|}
\hline 96 & 158 & 85 & 214 & 122 & 181 & 179 & 165 \\
\hline 242 & 75 & 241 & 92 & 55 & 110 & 154 & 242 \\
\hline 143 & 28 & 75 & 167 & 245 & 115 & 216 & 40 \\
\hline 45 & 176 & 252 & 40 & 235 & 248 & 59 & 38 \\
\hline 94 & 112 & 242 & 18 & 158 & 240 & 7 & 148 \\
\hline 48 & 19 & 85 & 212 & 61 & 153 & 9 & 217 \\
\hline 218 & 207 & 34 & 133 & 172 & 14 & 220 & 2 \\
\hline 22 & 10 & 23 & 14 & 5 & 16 & 11 & 30 \\
\hline
\end{tabular}

Tables 9 to 11 are the result of the End of File steganography process in image pixels. The selection can be done on Red, Green or Blue.

\section{CONCLUSION}

The use of cryptography in steganography is very useful to improve data security. The data hidden in the image does not necessarily have protection so that when data can be extracted from the image, very important information will be readable. By applying the Vernam technique, it will create encrypted and incomprehensible messages when successfully retrieved from the image.

\section{REFERENCES}

[1] R. Kumar dan R. C., "Analysis of Diffie Hellman Key Exchange Algorithm with Proposed Key Exchange Algorithm," International Journal of Emerging Trends \& Technology in Computer Science, vol. 4, no. 1, pp. 40-43, 2015.

[2] S. I. Chowdhury, S. A. M. Shohag dan H. Sahid, "A Secured Message Transaction Approach by Dynamic Hill Cipher Generation and Digest Concatenation," International Journal of Computer Applications, vol. 23, no. 9, pp. 25-31, 2011.

[3] C. Cachin, Digital Steganography, Switzerland: IBM Research, 2005.

[4] P. K. Y. P. S. M. S. \&. B. M. Lahane, "Data Security Using Visual Cryptography and Bit Plane Complexity Segmentation," International Journal of Emerging Engineering Research and Technology, vol. 2, no. 8, pp. 40-44, 20 November 2014.

[5] D. Nofriansyah dan R. Rahim, "Combination of Pixel Value Differencing Algorithm with Caesar Algorithm for Steganography,” International Journal of Research In Science \& Engineering, vol. 2, no. 6, pp. 153-159, 2016.

[6] E. Hariyanto dan R. Rahim, “Arnold's Cat Map Algorithm in Digital Image Encryption," International Journal of Science and Research, vol. 5, no. 10, pp. 1363-1365, 2016.

[7] A. P. U. Siahaan, "RC4 Technique in Visual Cryptography RGB Image Encryption," SSRG International Journal of Computer Science and Engineering, vol. 3, no. 7, pp. 1-6, 2016.

[8] B. Oktaviana dan A. P. U. Siahaan, "Three-Pass Protocol Implementation in Caesar Cipher Classic Cryptography," IOSR Journal of Computer Engineering, vol. 18, no. 4, pp. 26-29, 2016. 